\title{
Psychiatric Sequelae of Former “Comfort Women," Survivors of the Japanese Military Sexual Slavery during World War II
}

\author{
Jeewon Lee', Young-Sook Kwak², Yoon-Jung Kim³ ${ }^{3}$, Eun-Ji Kim², E Jin Park ${ }^{5}$, \\ Yunmi Shin ${ }^{6}$, Bun-Hee Lee ${ }^{7}$, So Hee Lee ${ }^{8}$, Hee Yeon Jung ${ }^{9}$, Inseon Lee ${ }^{10}$, \\ Jung Im Hwang ${ }^{10}$, Dongsik Kim ${ }^{10}$, and Soyoung Irene Lee ${ }^{1 凶}$ \\ 1'Department of Psychiatry, Soonchunhyang University Bucheon Hospital, Bucheon, Republic of Korea \\ ${ }^{2}$ Department of Psychiatry, Jeju National University, Jeju, Republic of Korea \\ ${ }^{3}$ Mentor Clinic, Seoul, Republic of Korea \\ ${ }^{4}$ Maumtodac Clinic, Ansan, Republic of Korea \\ ${ }^{5}$ Department of Psychiatry, Incheon St. Mary's Hospital, Incheon, Republic of Korea \\ ${ }^{6}$ Department of Psychiatry, Ajou University, Suwon, Republic of Korea \\ ${ }^{7}$ Department of Psychiatry, Seoul Metropolitan Enpyeong Hospital, Seoul, Republic of Korea \\ ${ }^{8}$ Department of Psychiatry, National Medical Center, Seoul, Republic of Korea \\ ${ }^{9}$ Department of Psychiatry, Seoul National University, Seoul, Republic of Korea \\ ${ }^{10}$ Korean Women's Development Institute, Seoul, Republic of Korea
}

\begin{abstract}
"Comfort women" refers to young women and girls who were forced into sexual slavery by the Imperial Japanese military during World War II. They were abducted from their homes in countries under Imperial Japanese rule, mostly from Korea, and the rest from China, Philippines, Malaysia, Taiwan, Indonesia, the Netherlands, etc. "Comfort women” endured extreme trauma involving rape, sexual torture, physical abuse, starvation, threats of death, and witnessed many others being tortured and killed. This article reviews all the studies that have investigated the psychiatric or psychosocial sequelae of the survivors of the Japanese military sexual slavery. Most importantly, a recent study which conducted a psychiatric evaluation on the former "comfort women" currently alive in South Korea is introduced. The participants' unmarried rate was relatively high and their total fertility rate was relatively low. Majority of the participants reported having no education and being the low economic status. They showed high current and lifetime prevalence of posttraumatic disorder, major depressive disorder, somatic symptom disorder, social anxiety disorder, panic disorder, and alcohol use disorder. Participants showed high suicidality and majority of the participants still reported being ashamed of being former "comfort women" after all these years. This article highlights the fact that the trauma has affected the mental health and social functioning of former "comfort women" throughout their lives, and even to the present day.

Psychiatry Investig 2018;15(4):336-343
\end{abstract}

Key Words Comfort women, Japanese military sexual slavery, Psychiatric sequelae, Posttraumatic stress disorder.

\section{INTRODUCTION}

The term "comfort women" refers to approximately 200,000 women who were forced into sexual slavery by the Imperial Japanese Army during World War II. ${ }^{1}$ Young women and girls, mostly between the ages of 11 and 20 , were abducted from their homes in countries under Imperial Japanese rule, most-

\footnotetext{
Received: July 21, 2017 Revised: October 11, 2017

Accepted: November 8, 2017

$\triangle$ Correspondence: Soyoung Irene Lee, MD, PhD

Department of Psychiatry, Soonchunhyang University Bucheon Hospital, 170 Jomaru-ro, Bucheon 14584, Republic of Korea

Tel: +82-32-621-5063, Fax: +82-32-621-6950, E-mail: irenelee@schmc.ac.kr

(a) This is an Open Access article distributed under the terms of the Creative Commons Attribution Non-Commercial License (http://creativecommons.org/licenses/bync/4.0) which permits unrestricted non-commercial use, distribution, and reproduction in any medium, provided the original work is properly cited.
}

ly from Korea, and the rest from China, Philippines, Malaysia, Taiwan, Indonesia, the Netherlands etc. ${ }^{2}$ They were detained in comfort stations and were forced to serve as sex slaves for the Japanese soldiers, being raped 10 to 50 times a day for years. ${ }^{3}$ They also suffered immeasurable pain from sexually transmitted diseases, aggressive treatment of these disease, forced abortion and sterilization, starvation, physical abuse, torture, threats of death, and approximately 75 percent are estimated to have died during the ordeal. ${ }^{4}$

When the war ended, the survived victims had to go on with their lives enduring the incurable physical and psychological wounds, as well as the social stigma. The "comfort women" issue was tabooed in the post-war decades and hidden by most of the survivors. In 1991, a Korean former "comfort woman" broke the silence and came forward publicly 
for the first time, seeking a formal apology and reparation from the Japanese government. ${ }^{3}$ Her action led hundreds of other women in Korea to come forward, and 239 women officially registered with the South Korean government as former "comfort women." Testimonies of many survivors revealed vivid details of their unbelievably cruel experience and the atrocities committed by the Japanese military. Since then, much research has been done investigating the concealed truth.

Nevertheless, studies on the survivors' mental health problems or psychosocial sequelae is scarce. Most literature on the "comfort women" have been focused on the historical facts and the political issues. Majority of the publication regarding "comfort women" are the testimonies of the survivors which reveal the extreme nature of the sexual violence and exploitation suffered by the survivors, but lack an analytical perspective. As former "comfort women" are a hard-toreach population, studies that do have an analytical perspective or a theoretical discussion on the psychological impact of the trauma are mostly analyses based on the published testimonies of the survivors.

This article reviews all the studies which conducted a direct evaluation on the survivors of the Japanese military sexual slavery in order to investigate the psychiatric or psychosocial sequelae of the trauma. Most importantly, a recent study which conducted a psychiatric evaluation on the former "comfort women" currently alive in South Korea is introduced.

\section{SUMMARY OF STUDIES ON THE PSYCHIATRIC OR PSYCHOSOCIAL SEQUELAE OF THE FORMER “COMFORT WOMEN"}

Currently available literature on "comfort women" were searched using the PubMed and the Korean databases such as the KoreaMed and Research Information Sharing Service
(RISS). The terms "comfort women" and "Japanese military sexual slavery" were used. All abstracts of publications through the three databases were screened for the search of the studies that investigated the long-term effects of the traumatic event on the survivors' mental health and social functioning. Studies that conducted a direct evaluation on a relatively large sample of the survivors were included. Analyses of the published testimonies of the survivors and case reports were excluded. Only the articles published in Korean or English were included.

Six studies had investigated the psychiatric or psychosocial sequelae of the survivors of the Japanese military sexual slavery (Table 1). Four studies conducted a psychiatric evaluation on the survivors and 2 studies conducted an in-depth qualitative interview with the survivors. Five studies are briefly reviewed, and the most recent study is thoroughly introduced in the next section, as the results of the study most accurately reflects the current status of the survivors.

In 1999, Shim conducted in-depth qualitative interviews with 6 survivors in order to examine the lives of the survivors after the return from the comfort stations. ${ }^{5}$ She found that after the war, the survivors were cut-off from their hometowns and their families. The study showed that survivors had difficulty making intimate relationships with friends and family and had poor living conditions. They couldn't live an ordinary life as a woman and had confusion in their identity. The factors that made them remain in silence for such a long time were their poor living conditions, broken family ties, and cultural factors that valued chastity. This study was among the first attempts to focus on the lives of the survivors after the trauma than the trauma itself. Since there were 199 registered survivors alive at the time, the small sample size is a limitation in generalizing the results of the study.

In 2003, Min et al. conducted a psychiatric evaluation on 26 former "comfort women" and compared them with a control group. ${ }^{6,7}$ Psychiatrists and a clinical psychologist used the Structured Clinical Interview for DSM-IV Axis I Disorders

Table 1. Summary of the studies on the psychiatric or psychosocial sequelae of the survivors of the Japanese military sexual slavery

\begin{tabular}{lcclc}
\hline \multicolumn{1}{c}{ Author } & Year & Number of participants & \multicolumn{1}{c}{ Method/tools } & Language \\
\hline Shim $^{5}$ & 1999 & 6 & Qualitative interview & Korean \\
Min et al. ${ }^{6}$ & 2003 & 26 & SCID-I, GDS, PS scale of MMPI, STAXI, Rorschach test & Korean, English \\
Park et al. $^{9}$ & 2013 & 16 & Qualitative interview & English \\
Kim et al. $^{10}$ & 2014 & 12 & PDS, EQ-5D & Korean \\
Lee et al. ${ }^{12}$ & 2015 & 5 & MINI, HAMD, HAMA, POREST, MMSE & Korean \\
Lee et al. ${ }^{13}$ & 2016 & 20 & SCID-I, Stigma Scale & Korean \\
\hline
\end{tabular}

SCID-I: Structured Clinical Interview for DSM-IV axis I disorders, GDS: Geriatric Depression Scale, PS: Paranoid scale, MMPI: Minnesota Multiphasic Personality Inventory, STAXI: State-Trait Anxiety Expression Inventory, PDS: Posttraumatic stress Diagnostic Scale, EQ-5D: EuroQol-5 Dimension, MINI: Mini-International Neuropsychiatric Interview, HAMD: Hamilton Depression rating scale, HAMA: Hamilton Anxiety rating scale, POREST: Positive Resources Test, MMSE: Mini-Mental State Examination 
(SCID-I) to diagnose posttraumatic stress disorder in the participants. The SCID-I is a standardized diagnostic interview widely used to assess psychiatric disorders and the Korean version has been validated. ${ }^{8}$ Self-reports consisting of Geriatric Depression Scale (GDS), paranoid state scale from Minesota Multiphasic Personality Inventory (MMPI), State and Trait Anger Expression Inventory (STAXI) were also used. All 26 participants had suffered from symptoms of posttraumatic stress disorder at least once in their lives, and $30.8 \%$ were diagnosed with posttraumatic stress disorder at the time. PTSD symptom profiles of former "comfort women" were characterized by avoidance, recollection, and anger. Former "comfort women" had impairments in anger control and were more depressed than the control group. In Rorschach test, former "comfort women" showed higher scores on responses that reflect impulse emotions, anxiety, aggressive movement content than the control group. Also, former "comfort women" recorded significantly higher mean scores than the control group on sex response, morbid response, and trauma content index. This study shed light on the psychiatric sequelae of the former "comfort women." The limitation of the study was that convenience sampling was used and 26 participants were chosen among the 151 registered survivors alive at the time. Also, other psychiatric disorders other than posttraumatic stress disorder were not evaluated.

In 2013, Park et al. ${ }^{9}$ conducted semi-structured qualitative interviews with 16 former "comfort women" in order to evaluate the impact of this early-life trauma on the lives of the survivors. The study provided understanding of the types and depth of the trauma, as well as the impact it had on the life course of the survivors. The study revealed that as the consequence of the trauma, the survivors had strained relationships with men, difficulties in having children, physical pain, and emotional suffering. Feelings of intense loneliness, sense of remorse, resentment and anger were the common emotional distress the survivors showed. The limitation of the study was that convenience and snowball sampling was used which may have resulted in response bias. There were 59 registered survivors alive at the time. Also, the data was translated from Korean to English prior to analysis which could have affected the analysis of the result.

In 2014, Korean Women's Development Institute evaluated 12 survivors for posttraumatic stress disorder. ${ }^{10}$ Modified PDS scales were used for the evaluation. There were 48 registered survivors alive at the time in South Korea. 3 (25\%) survivors were found to have all 3 symptoms of reexperience, avoidance, and hyperarousal. Subjective well-being and satisfaction with life were also measured in a 5-point scale. Both scores of subjective well-being and satisfaction with life were both highest (3.6 and 3.4 respectively) before the abduction and lowest (1.6 and 0.8 respectively) during captivity. The scores rose after returning from the comfort stations but stayed lower than 2.5 throughout their lives. The generic health status measured by EQ-5D was 0.64 in the participants; while the mean EQ-5D index in the elderly population has been reported to be 0.82 in South Korea. ${ }^{11}$ The limitation of the study was that the diagnosis of posttraumatic stress disorder was not made by diagnostic interviews with psychiatrists or clinical psychologists. Also, the lifetime prevalence of the posttraumatic stress disorder was not evaluated.

In 2015, as a substudy of "A Comprehensive Study to Resolve the Japanese Military 'Comfort Women' Issue (I)" by the Korean Women's Development Institute, psychiatrists conducted a semi-structured psychiatric interview with 5 survivors, using Mini International Neuropsychiatric Interview (MINI). ${ }^{12}$ Several clinician-administered scales such as Hamilton Depression Scale (HAMD), Hamilton Anxiety Scale (HAMA), Short PTSD Rating Interview (Sprint), Positive Resources Test (POREST), Mini Mental Status Examination (MMSE) were also used. All 5 survivors showed symptoms of posttraumatic stress disorder such as reexperience, avoidance, and hyperarousal, as well as chronic depression, anxiety, rage, humiliation, and insomnia. The sample size was too small and the investigators didn't consider lifetime prevalence of the psychiatric disorders including the posttraumatic stress disorder.

\section{PSYCHIATRIC SEQUELAE OF THE FORMER "COMFORT WOMEN" CURRENTLY ALIVE IN SOUTH KOREA}

As a substudy of "A Comprehensive Study to Resolve the Japanese Military 'Comfort Women' Issue (II)" by the Korean Women's Development Institute, psychiatrists from the Special Committee for Gender-Equality and Family of Korean Neuropsychiatry Association conducted a psychiatric evaluation on the former "comfort women" currently alive in South Korea. ${ }^{13}$ Gender-Equality and Family Department of the Korean government contacted all the registered survivors currently alive, which was 38 in July 2016, asking for their participation in the study. Seven survivors were excluded because they had a physical or mental illness which made it impossible to participate in the study. Eleven survivors refused to participate in the study; 5 had personal reasons, 4 had political differences from the government, and 2 had health problems. Finally, 20 survivors agreed to participate in the study.

Interviews took place at the homes of the participants between July and August 2016. A psychiatric interview was conducted to review the lives of the participants focusing on the psychosocial sequelae throughout their lives. The SCID-I was 
used to assess current (30 days) and lifetime diagnosis of psychiatric disorders including posttraumatic stress disorder. ${ }^{14}$ Because the participants were in their 80's or 90's, recall bias and memory gaps were expected. To enhance the validity and reliability, a group of two, consisting of two psychiatrists or one psychiatrist and one clinical psychologist conducted the psychiatric interview. Two interviewers assessed separately during the interview, and made a consensus afterwards. A close family or a relative was also interviewed to attain objective information and enhance reliability.

\section{Sociodemographic characteristics}

Sociodemographic characteristics of the participants in this study are shown in Table 2 . The mean age of the participants was 89.45 ( $\mathrm{SD}=2.96)$, ranging from 86 to 97 years of age. ${ }^{14}$ (70\%) participants had been widowed, $1(5 \%)$ had been divorced, and 5 (25\%) was never married. For women who were mostly born in the 1920's, it was very unlikely to stay unmarried. All women were expected to get married and bear children at the time. In a 2009 longitudinal study in South Korea, the unmarried rate of 708 women between 75 and 85 years of age was $0.38 \% .{ }^{15}$ Therefore, the marriage rate of the

Table 2. Sociodemographic characteristics of the participants $(\mathrm{N}=20)$

\begin{tabular}{|c|c|c|c|}
\hline \multicolumn{2}{|c|}{ Variables } & Mean & $\mathrm{SD}$ \\
\hline \multicolumn{2}{|l|}{ Age } & 89.45 & 2.96 \\
\hline \multicolumn{2}{|c|}{ Number of children } & 2.65 & 2.23 \\
\hline \multicolumn{2}{|c|}{ Number of biological children } & 1.80 & 2.09 \\
\hline \multicolumn{2}{|c|}{ Number of non-biological children } & 0.85 & 1.63 \\
\hline & & & N (\%) \\
\hline \multirow[t]{4}{*}{ Marital status } & Married & & $0(0)$ \\
\hline & Widowed & & $14(70)$ \\
\hline & Divorced & & $1(5)$ \\
\hline & Never been married & & $5(25)$ \\
\hline \multirow[t]{5}{*}{ Education level } & Non & & $17(85)$ \\
\hline & Elementary school & & $2(10)$ \\
\hline & Middle school & & $1(5)$ \\
\hline & High school & & $0(0)$ \\
\hline & University or more & & $0(0)$ \\
\hline \multirow[t]{3}{*}{ Economic status } & Low & & $15(75)$ \\
\hline & Middle & & $5(25)$ \\
\hline & High & & $0(0)$ \\
\hline \multirow[t]{5}{*}{ Living Status } & Home- Living alone & & $7(35)$ \\
\hline & Home-Living with $\mathrm{f}_{\mathrm{a}}$ & y/relative & $6(30)$ \\
\hline & Group Facility & & $2(10)$ \\
\hline & Hospital & & $3(15)$ \\
\hline & Other & & $2(10)$ \\
\hline
\end{tabular}

participants compared to that of the similar age group in the general population is very low. Also, among the participants who had been married, very few had a normal marriage. Most of them got married to men who were much older, and with prior marriage experience and sometimes children of their own. Furthermore, many of the cases were more of an affair with a married man than a real marriage. Many participants were maltreated by their spouses and were victims of domestic violence.

The mean number of biological children was $1.80(\mathrm{SD}=2.09)$ in the participants. If you assume the child-bearing age of the participants to be up to their 40's, it would be until the 1960's. Total fertility rate (the average number of children that would be born to a woman over her lifetime) in the 1950's and the 1960 's was nearly six children per woman in South Korea. ${ }^{16}$ Relatively low fertility rate of the participants could be due to the high unmarried rate of the participants. Also, many participants suffered from sexually-transmitted diseases, aggressive treatment and forced abortions during their years as a "comfort women," which would have affected their fertility.

\section{Posttraumatic stress disorder}

Current and lifetime prevalence rate of posttraumatic stress disorder in the participants were $65 \%$ and $90 \%$, respectively (Table 3). This rate is relatively high compared to other prior studies on World War II-related traumatization, including the survivors of massive war rapes and even the Holocaust survivors. A study on 316 elderly Austrians (born before 1946) showed that even though $97.5 \%$ of the sample reported at least one lifetime trauma, PTSD was present in $1.9 \%$, and $13.9 \%$ taking subthreshold posttraumatic stress disorder into account. ${ }^{17}$ A study on 27 elderly German women who survived the mass rapes committed by soldiers at the end of World War II, 19\% reported a significant current posttraumatic stress symptoms indicating a possible posttraumatic stress disorder at the time of the study. ${ }^{18}$ In the Sydney Holocaust study in 2003, among 100 Holocaust survivors over 60 years old, the prevalence rate of posttraumatic stress disorder was $39.0 \%{ }^{19}$

Table 3. Current and lifetime prevalence of psychiatric disorders

\begin{tabular}{lcc}
\hline \multicolumn{1}{c}{ Diagnosis } & Current & Lifetime \\
& $\mathrm{N}(\%)$ & $\mathrm{N}(\%)$ \\
\hline Posttraumatic stress disorder & $13(65)$ & $18(90)$ \\
Major depressive disorder & $2(10)$ & $9(45)$ \\
Somatic symptom disorder & $5(25)$ & $5(25)$ \\
Social anxiety disorder & $1(5)$ & $4(20)$ \\
Panic disorder & $1(5)$ & $3(15)$ \\
Alcohol use disorder & $0(0)$ & $3(15)$ \\
\hline
\end{tabular}


The first reason for such high prevalence rate of posttraumatic stress disorder in the former "comfort women" would be because they were victims of massive sexual violence. Rape is a trauma associated with one of the highest risks of developing posttraumatic stress disorder and related psychiatric conditions. ${ }^{20}$ Women with histories of sexual assault are found to have posttraumatic stress disorder at three times the rate of women without such histories. ${ }^{21}$ One study on 27 elderly wartime rape survivors showed that women exposed to sexual violence during World War II reported greater severity of posttraumatic stress disorder-related avoidance and hyperarousal symptoms, as well as anxiety, compared to female with non-sexual World War II trauma. ${ }^{22}$ Further, the effect of sexual abuse is cumulative, thus severity of posttraumatic stress disorder symptoms increases with more incidents of abuse and increased severity of abuse $\mathrm{e}^{23}$ Many documents report that "comfort women" were forced to have sex with as many as 30-40 soldiers per day. ${ }^{9}$ Therefore, it is not surprising that the prevalence rate of posttraumatic stress disorder in former "comfort women" are higher than other victims of war trauma or even the Holocaust survivors.

Second, the fact that most former "comfort women" were in their adolescence at the time of the trauma would be crucial. Early-life trauma is reported to be more impactful, resulting in more lasting and pernicious effects over the life course. ${ }^{24}$ All the participants in this study reported being abducted when they were teenagers. With lack of mature coping resources and adaptive skills, they would have used immature methods of coping skills to deal with the formidable stressors, such as disengagement and avoidant methods. Victims of child sexual abuse tend to use disengagement methods of coping such as denial, avoidance, wishful thinking, and self-criticism, which negatively affects psychological recovery from a traumatic experience. ${ }^{25}$ A study on Holocaust survivors showed that age at the time of trauma and cumulative number of stressful events were associated with increased symptoms of psychogenic amnesia, hypervigilance, and emotional detachment. ${ }^{26}$

Third, the survivors are still being re-traumatized due to the unsettled controversy regarding the "comfort women" issue. Unlike issues like the Holocaust, which the responsible individuals have been legally punished and the German government has accepted full responsibility and apologized repeatedly, the Japanese government still seems reluctant in taking full responsibility and apologizing sincerely to the victims. There are three requirements that supports the integrity of an apology: the perpetrator's willingness to take responsibility for the action, acknowledging the suffering experienced by the victims, and willingness to pledge that the act will not be repeated. ${ }^{27}$ However, most "comfort women" feel they have not received proper and sufficient apology from the Japanese government. The perpetrators have not been legally prosecuted, Japanese history textbooks rarely contain references to the "comfort women" issue, and some government authorities and public figures still attempts to defame the victims by repeated denials of the events. As apology is known to be a necessary prerequisite to healing and recovery from the trauma, ${ }^{28}$ the ongoing dispute over the "comfort women" issue seems to re-traumatize the survivors and contribute in their persisting symptoms of posttraumatic stress disorder.

\section{Other psychiatric disorders}

The lifetime and current prevalence of major depressive disorder in the participants were $45 \%$ and $10 \%$, respectively (Table 3). In a Korean study involving 1,118 Korean elders in 2010, the prevalence rate of major depressive disorder in those older than 80 years old was $1.39 \% .^{29}$ The lifetime and current prevalence of social anxiety disorder in the participants were $20 \%$ and $5 \%$, respectively. The lifetime and current prevalence of panic disorder in the participants were $15 \%$ and $5 \%$, respectively. The lifetime and current prevalence of alcohol use disorder in the participants were $15 \%$ and $0 \%$, respectively. Eventually, $90 \%$ of the participants suffered from at least 1 psychiatric disorder throughout their lives, and 70\% could still be diagnosed with at least 1 psychiatric disorder currently.

The above rates are relatively higher than the rates reported in the general population in South Korea. According to a 2011 study in South Korea which assessed 6,022 adults, aged 18 to 74 years, using the Composite International Diagnostic Interview (CIDI), lifetime and 12-month prevalence of female adults were as follows ${ }^{30}$ : major depressive disorder $9.1 \%$ and $4.3 \%$, respectively; social phobia $0.6 \%$ and $0.3 \%$, respectively; panic disorder, $0.4 \%$ and $0.3 \%$, respectively; alcohol abuse $3.1 \%$ and $0.9 \%$, respectively. The prevalence rates of any mental disorders were $23.5 \%$ and $15.8 \%$, respectively. In a study of 4,451 Australian women, women with genderbased violence histories showed high rates of lifetime mood, anxiety, and substance use disorders relative to those without such exposure. $^{31}$

Somatic symptom disorder was also found prevalent in the participants; the lifetime and current prevalence rates were $30 \%$ and $25 \%$, respectively. A comprehensive meta-analysis on association between sexual abuse and lifetime prevalence of somatic disorders showed significant associations between rape and lifetime diagnosis of several somatic disorders such as fibromyalgia, chronic pelvic pain, and functional gastrointestinal disorders. ${ }^{32}$

\section{Suicidality}

The lifetime and current (30 days) prevalence of suicidal ideation and suicidal attempt were asked as yes or no ques- 
tions. The lifetime prevalence of suicidal ideation and suicide attempts in the participants were $70 \%$ and $25 \%$, respectively. The results are much higher compared to the data reported in the general population in South Korea. In a study of 2,964 Korean adults, estimates of the lifetime prevalence of suicidal ideation and suicide attempts in female were $26.5 \%$ and $6.8 \%$, respectively. ${ }^{33}$ Women who experienced sexual assault have been reported to have higher rates of suicide attempts. ${ }^{31}$ In a study of 83 Holocaust survivors, Holocaust survivors showed higher suicidality, reporting $9.7 \%$ prevalence rate of suicide attempt, compared to $0 \%$ in the control group. ${ }^{34}$ Further, $30 \%$ of the participants reported currently having suicidal ideation. No one had attempted suicide during the last 30 days.

\section{Stigma}

To assess the internalized stigma of the victims, the stigma scale based on the scale measuring, stigma, betrayal, and powerlessness previously developed for assessing the dynamics among women with a history of child sexual abuse was used. ${ }^{35}$ The scale measuring stigma, betrayal, and powerlessness contained specific 19 questions to assess how victims feel about their childhood sexual abuse experience from their adult perspective. The stigma scale used in this study was the expanded version developed by Gibson and Leitenberg, containing 9 questions. ${ }^{25}$ The questions were read out to the participants during the interview and used a 5-point Likert scale ranging from "never" to "always." However, most participants had a hard time choosing between the 5-point Likert scale. To enhance the reliability, the answers from 1 (never) to 3 (sometimes) were considered as "no" and 4 (frequently) to 5 (always) were considered as "yes." 15 (75\%) answered they still feel ashamed about the experience and 14 (70\%) reported they think others would blame them for what happened (Table 4). 13 (65\%) concerned that other people will think negative about their sexuality if they found out they were former "comfort women". 12 (60\%) answered they were con- cerned about what other people would think of them and how they would react if they found out what had happened. 12 (60\%) still felt embarrassed about telling people about their "comfort women" experience.

\section{Psychological sequelae}

The common psychological sequelae of the trauma that had a lifelong impact on the participants were as following.

First, survivors suffered from lifelong shame, guilt and stigma of being former "comfort women." At the time of the torture, the former "comfort women" would have experienced a profound loss of dignity and power, feeling humiliation and shame. After the trauma, as part of negative self-attributional process, the survivors could have blamed themselves, suffering from posttraumatic shame and guilt. For a very long time, they hid in silence being afraid to be disclosed as former "comfort women." The stigma of being a former "comfort woman" can be seen as fear of being judged and shamed by others, but it could also be explained as externalized projections of one's own self-condemnation and hatred. ${ }^{36}$

Second, survivors showed cognition and behaviors of learned helplessness. Participants endured long-lasting trauma where perpetrators were so powerful and the situation was impossible for them to escape or avoid the atrocities. They witnessed others being brutally tortured or killed after attempting to escape. Through this experience, participants would have acquired learned helplessness, losing trust in the world and others, perceiving life as unpredictable and uncontrollable. Many of the participants met spouses that were abusive, including married men who treated them badly. However, probably due to their learned helplessness and low selfesteem, they did not seek to escape from such situation and accepted the maltreatment. One participant who actually escaped from the "comfort station" by jumping on a train showed the least psychopathology and wasn't diagnosed with any psychiatric disorder. It could be because she didn't acquire learned helplessness by escaping from the traumatic situa-

Table 4. Results of the stigma scale

\begin{tabular}{|c|c|}
\hline Questions & $\mathrm{N}(\%)$ \\
\hline How ashamed do you feel about this experience? & $15(75)$ \\
\hline How much do you think others would blame you for what happened? & $7(35)$ \\
\hline How much do you think you are different from other women because of this experience? & $11(55)$ \\
\hline How much do you feel tainted (“dirtied”) by this experience? & $14(70)$ \\
\hline How concerned are you that other people will think something negative about your sexuality if they found out? & $13(65)$ \\
\hline How concerned are you about what other people would think of you if they found out what happened? & $12(60)$ \\
\hline How embarrassed are you about telling people what happened? & $12(60)$ \\
\hline How concerned are you about people not respecting you as much if they were to find out what happened? & $9(45)$ \\
\hline How concerned are you about how other people would react if they were to find out what happened? & $12(60)$ \\
\hline
\end{tabular}


tion for herself.

Third, survivors showed difficulties in emotional regulation and impulse control. Children and relatives of the participants recalled memories of the participants being angry and irritated most of the times, not knowing when they would explode and start yelling at others. This unstable emotion and impulsivity seemed to have worsened when one was reminded of the trauma by an external stimulus or an intrusive thought. Previous studies have reported increased impulsivity is highly associated with posttraumatic stress disorder. ${ }^{37,38}$

\section{Limitations}

Several limitations of this study should be considered. First, the relatively small sample size did not yield sufficient statistical power. Second, the participants constitute a selected sample, since it comprised those who were healthy enough to reach a relatively advanced age. Third, 70 years have passed since the traumatic experience, and the elderly participants could have suffered from recall bias. Fourth, lack of a control group did not reveal statistically significant association between the trauma and the diagnosis of the psychiatric disorders. Fifth, due to the advanced age of the participants and their limitation in cognitive function, only the diagnosis of the psychiatric disorders was evaluated, and the severity of the symptoms, as well as the severity of the stigma could not be assessed accurately.

\section{Implications}

Notwithstanding these limitations, this study has many implications as it is one of the very few attempts to examine the long-lasting psychiatric sequelae of former "comfort women." First, all registered former "comfort women" still alive in South Korea were contacted for the participation in the study. Second, a psychiatrist conducted an in-depth psychiatric interview with all the participants. Third, many psychiatric disorders including posttraumatic stress disorder, major depressive disorder, social anxiety disorder, panic disorder, somatic symptom disorder, and alcohol use disorder were evaluated. Fourth, not only current but also lifetime prevalence of psychopathologies and diagnoses of psychiatric disorders were evaluated. Fifth, psychological sequelae including shame, guilt and stigma of the participants was also examined.

\section{CONCLUSION}

Seven decades have passed since the end of the World War II. Majority of the former "comfort women" have passed away, currently leaving only 37 registered survivors in South Korea. This article summarizes the psychiatric and psychosocial sequelae of the survivors. It is evident that the trauma of the
Japanese military sexual slavery has affected the mental health and social functioning of the survivors throughout their lives, and even to the present day. Thus, the trauma should not be considered a matter of the past, but of today. As most of the studies had been published in Korean, this article could enlighten many others who were not familiar with the issue. Further, this article could also provide insights into the consequences of trauma of victims of sexual trafficking, which is still happening around the world.

\section{Acknowledgments}

This work was supported by Korean Women's Development Institute and Soonchunhyang University Research Fund.

\section{REFERENCES}

1. Soh CS. The Korean "comfort women": movement for redress. Asian Survey 1996;36:1226-1240.

2. Yoshimi Y. Comfort Women: Sexual Slavery in the Japanese Military during World War II. New York: Columbia University Press; 2000.

3. Joo HJS. Comfort women in human rights discourse: fetishized testimonies, small museums, and the politics of thin description. Rev Educ Pedagogy Cult Stud 2015;37:166-183.

4. de Brouwer AM. Supranational Criminal Prosecution of Sexual Violence: The ICC and the Practice of the ICTY and the ICTR. Oxford: Intersentia; 2005.

5. Shim YH. From silence to testimony: the life of the Korean 'comfort women' after the return. Korean Stud 2000;23:115-146.

6. Min SK, Lee CH, Kim JY, Shim EJ. Posttraumatic stress disorder of former comfort women for Japanese army during World War II. J Korean Neuropsychiatr Assoc 2004;43:740-748.

7. Lee CH, Kim JY, Sim EJ. Posttraumatic stress disorder in former "comfort fomen". Isr J Psychiatry Relat Sci 2011;48:161-169.

8. Hahn OS, Ahn JH, Song SH, Cho MJ, Kim JK, Bae JN, et al. Development of Korean version of structured clinical interview schedule for DSM-IV axis I disorder: interrater reliability. J Korean Neuropsychiatr Assoc 2000;39:362-372.

9. Park JH, Lee K, Hand MD, Anderson KA, Schleitwiler TE. Korean survivors of the Japanese "comfort women" system: understanding the lifelong consequences of early life trauma. J Gerontol Soc Work 2016; 59:332-348.

10. Kim DS, Hwang JI, Jang SN, Tong CY. Health Status for the Victims of Japanese Military Sexual Slavery and Policy Implications. Seoul: Korean Women's Development Institute; 2014.

11. Kim HR. Health-related quality of life and its affecting factors among the aged in one Korean community. Korean J Health Serv Manag 2013; 7:167-178.

12. Lee IS, Hwang JI, Yang AK, Kim DS, Kang JS, Cho YJ. A Comprehensive Study to Resolve the Japanese Military 'Comfort Women' Issue (I). Seoul: Korean Women's Development Institute; 2016.

13. Lee IS, Hwang JI, Kim DS, Kang JS, Cho YJ. A Comprehensive Study to Resolve the Japanese Military 'Comfort Women' Issue (II). Seoul: Korean Women's Development Institute; 2016.

14. First M, Williams J, Karg R, Spitzer R. Structured Clinical Interview for DSM-5-Research Version (SCID-5 for DSM-5, research version; SCID-5-RV). Arlington, VA: American Psychiatric Association; 2015.

15. Jang SN, Kawachi I, Chang J, Boo K, Shin HG, Lee H, et al. Marital status, gender, and depression: analysis of the baseline survey of the Korean Longitudinal Study of Ageing (KLoSA). Soc Sci Med 2009;69:16081615.

16. Choe MK, Park KA. Fertility decline in South Korea: forty years of policy-behavior dialogue. Kor J Popul Stud 2006;29:1-26. 
17. Glück TM, Tran US, Lueger-Schuster B. PTSD and trauma in Austrias elderly: influence of wartime experiences, postwar zone of occupation, and life time traumatization on today's mental health status-an interdisciplinary approach. Eur J Psychotraumatol 2012;3.

18. Kuwert P, Klauer T, Eichhorn S, Grundke E, Dudeck M, Schomerus G, et al. Trauma and current posttraumatic stress symptoms in elderly German women who experienced wartime rapes in 1945. J Nerv Ment Dis 2010;198:450-451.

19. Joffe C, Brodaty H, Luscombe G, Ehrlich F. The Sydney Holocaust study: posttraumatic stress disorder and other psychosocial morbidity in an aged community sample. J Trauma Stress 2003;16:39-47.

20. Campbell R, Wasco SM. Understanding rape and sexual assault: 20 years of progress and future directions. J Interper Viol 2005;20:127-131.

21. Hedtke KA, Ruggiero KJ, Fitzgerald MM, Zinzow HM, Saunders BE, Resnick HS, et al. A longitudinal investigation of interpersonal violence in relation to mental health and substance use. J Consult Clin Psychol 2008;76:633-647.

22. Kuwert P, Glaesmer H, Eichhorn S, Grundke E, Pietrzak RH, Freyberger HJ, et al. Long-term effects of conflict-related sexual violence compared with non-sexual war trauma in female world war II survivors: a matched pairs study. Arch Sex Behav 2014;43:1059-1064.

23. Follette VM, Polusny MA, Bechtle AE, Naugle AE. Cumulative trauma: the impact of child sexual abuse, adult sexual assault, and spouse abuse. J Trauma Stress 1996;9:25-35.

24. Ogle CM, Rubin DC, Siegler IC. The impact of the developmental timing of trauma exposure on PTSD symptoms and psychosocial functioning among older adults. Dev Psychol 2013;49:2191-2200.

25. Gibson LE, Leitenberg H. The impact of child sexual abuse and stigma on methods of coping with sexual assault among undergraduate women. Child Abuse Negl 2001;25:1343-1361.

26. Yehuda R, Schmeidler J, Siever LJ, Binder-Brynes K, Elkin A. Individual differences in posttraumatic stress disorder symptom profiles in Holocaust survivors in concentration camps or in hiding. J Trauma Stress 1997;10:453-463.

27. Regehr C, Gutheil T. Apology, justice, and trauma recovery. J Am Acad
Psychiatry Law 2002;30:425-430.

28. Taft L. Apology subverted: the commodification of apology. Yale Law J 2000;109:1135-1160.

29. Park JH, Lee JJ, Lee SB, Huh Y, Choi EA, Youn JC, et al. Prevalence of major depressive disorder and minor depressive disorder in an elderly Korean population: results from the Korean Longitudinal Study on Health and Aging (KLoSHA). J Affect Disord 2010;125:234-240.

30. Cho MJ, Seong SJ, Park JE, Chung IW, Lee YM, Bae A, et al. Prevalence and correlates of DSM-IV mental disorders in South Korean adults: the Korean epidemiologic catchment area study 2011. Psychiatry Investig 2015;12:164-170.

31. Rees S, Silove D, Chey T, Ivancic L, Steel Z, Creamer M, et al. Lifetime prevalence of gender-based violence in women and the relationship with mental disorders and psychosocial function. JAMA 2011;306:513-521.

32. Paras ML, Murad MH, Chen LP, Goranson EN, Sattler AL, Colbenson $\mathrm{KM}$, et al. Sexual abuse and lifetime diagnosis of somatic disorders: a systematic review and meta-analysis. JAMA 2009;302:550-561.

33. Bagalkot TR, Park JI, Kim HT, Kim HM, Kim MS, Yoon MS, et al. Lifetime prevalence of and risk factors for suicidal ideation and suicide attempts in a Korean community sample. Psychiatry 2014;77:360-373.

34. Ablin J, Cohen H, Eisinger M, Buskila D. Holocaust survivors: the pain behind the agony. Increased prevalence of fibromyalgia among Holocaust survivors. Clin Exp Rheumatol 2010;28(6 Suppl 63):S51-S56.

35. Coffey P, Leitenberg H, Henning K, Turner T, Bennett RT. Mediators of the long-term impact of child sexual abuse: perceived stigma, betrayal, powerlessness, and self-blame. Child Abuse Negl 1996;20:447-455.

36. Wilson JP, Droždek B, Turkovic S. Posttraumatic shame and guilt. Trauma Violence Abuse 2006;7:122-141.

37. Netto LR, Pereira JL, Nogueira JF, Cavalcanti-Ribeiro P, Santana RC, Teles CA, et al. Impulsivity is relevant for trauma exposure and PTSD symptoms in a non-clinical population. Psychiatry Res 2016;239:204211.

38. Stanford MS, Mathias CW, Dougherty DM, Lake SL, Anderson NE, Patton JH. Fifty years of the Barratt Impulsiveness Scale: an update and review. Pers Individ Dif 2009;47:385-395. 